\title{
Relação entre a formação de radicais livres e a doença de Alzheimer: revisão sistemática
}

\author{
Relationship between free radicals formation and Alzheimer's disease: systematic \\ review
}

\author{
Paloma Herranz de Souza ${ }^{1 *}$, Maria Eugenia Alcântara Albano ${ }^{1}$, Lucia Elaine Ranieri Cortez², Diógenes \\ Aparício Garcia Cortez ${ }^{3}$
}

Acadêmica de Medicina da UniCesumar, Maringá-PR.; '2Doutora. Docente e Pesquisadora do Programa de Pósgraduação em Promoção da Saúde e do Curso de Medicina da UniCesumar; ${ }^{3}$ Doutor. Docente e Pesquisador do Programa de Pós-graduação em Promoção da Saúde da UniCesumar

\begin{abstract}
Resumo
Objetivo: realizar uma revisão sistemática sobre a relação entre os radicais livres e a doença de Alzheimer. Metodologia: a identificação dos artigos foi baseada nas diretrizes propostas pela declaração PRISMA e realizada em PubMed, Medline, Lilacs, IBECS e SciELO, com publicações entre 2006 e janeiro de 2016. Foram incluídos artigos que abordaram o acúmulo de radicais livres durante o envelhecimento e a relação entre o estresse oxidativo e a doença de Alzheimer. Resultados: 28 artigos, com resultados variados conforme os ensaios clínicos realizados e suas características e objetivos específicos, demonstrando envolvimento multissistêmico no estresse oxidativo. Conclusões: o estresse oxidativo celular que ocorre no envelhecimento é exacerbado na doença de Alzheimer devido ao acúmulo de peptídeo $\beta$-amiloide, principalmente na região do hipocampo, provocando os sinais clínicos da doença.

Palavras-chave: Envelhecimento. Estresse Oxidativo. Antioxidantes. Demência.
\end{abstract}

\begin{abstract}
Objective: to perform a systematic review of the relationship between free radicals and Alzheimer's disease. Methodology: the identification of articles was based on the guideline proposed by the PRISMA statement and done in PubMed, Medline, Lilacs, IBECS and SCIELO with publications between 2006 and January 2016. Included articles addressed the accumulation of free radicals during aging and the relationship between oxidative stress and Alzheimer's disease. Results: 28 articles, with varying results according to clinical trials and their specific characteristics and objectives, demonstrating multisystemic involvement in oxidative stress. Conclusions: the cellular oxidative stress that occurs in aging is exacerbated in Alzheimer's disease due to the accumulation of B-amyloid peptide, mainly in the hippocampus region, leading to clinical signs of the disease.
\end{abstract}

Keywords: Aging. Oxidative Stress. Antioxidant. Dementia.

\section{INTRODUÇÃO}

O envelhecimento da população é uma consequência do aumento do número de idosos e da diminuição de jovens, situação antiga em países desenvolvidos e recente no Brasil, e que é referida no Índice de Envelhecimento da População com aumento de mais de $40 \%$ entre 2001 e 2009. ${ }^{1}$ Tal aumento resulta em mudança do perfil epidemiológico do país, que passa a ser caracterizado pelas doenças crônicas, como a doença de Alzheimer (DA). ${ }^{2} \mathrm{O}$ aumento da expectativa de vida reflete no aumento de casos da DA, já que a prevalência das demências dobra a cada cinco anos, a partir dos 65 anos de idade, e tem seu ápice a partir dos 90 anos. ${ }^{3}$

A senescência está associada à redução da capacidade funcional das mitocôndrias, processo fisiológico que

Correspondente/Corresponding: Lucia Elaine Ranieri Cortez* - End: Av. Guedner, 1610 - Jardim Aclimação, Maringá-Pará - Tel: (44)99931-4409 E-mail: lucia.cortez@unicesumar.edu.br ocorre com o passar dos anos, sendo essa relação descrita como teoria dos radicais livres: as espécies reativas de oxigênio (EROs, ou reactive oxygen species - ROS), são as maiores causas do processo de envelhecimento. ${ }^{4}$ As EROs são produzidas durante a cadeia respiratória mitocondrial, tendo tanto produção aumentada como eliminação diminuída com o passar dos anos. Por serem moléculas extremamente reativas, passam a provocar lesões oxidativas nos lipídios, proteínas e DNA, o que acaba causando disfunção celular progressiva dos tecidos e do código genético..$^{4-6}$

O sistema antioxidante do organismo tem como função a minimização ou até remoção de EROs, íons metálicos e outros componentes oxidantes potencialmente reativos, por meio de interferências em algum dos estágios do processo de oxidação. Um dos agentes mais importantes do sistema antioxidante é a GSH (glutationa reduzida), que quando em contato com agentes reativos é oxidada, formando a GSSG (glutationa oxidada) - se houver excesso de oxidantes e/ou deficiência do sis- 
tema antioxidante, não haverá a recuperação de GSH, com alteração no equilíbrio GSH/GSSG e consequente ambiente oxidativo. Assim, torna-se favorável a formação de pontes dissulfeto nas proteínas transportadoras, o que causa prejuízo às suas funções devido à oxidação promovida por essas estruturas formadas. ${ }^{6}$

Os mecanismos de antioxidação também envolvem as vitaminas C (ascorbato) e E (tocoferol), sendo essa a principal substância antioxidante presente na membrana celular, prevenindo a peroxidação lipídica e, consequentemente, o estresse oxidativo desencadeado por ela. ${ }^{7}$ As vitaminas agem contra os radicais livres oferecendo a eles o elétron que lhes falta para sua estabilização, fazendo com que eles não ataquem outros compostos celulares em busca de seus elétrons. ${ }^{8}$

$\mathrm{O}$ aumento do estresse oxidativo no cérebro associado à diminuição do sistema antioxidante leva ao acúmulo de DNA alterado, gatilho para a apoptose celular e característica da perda neuronal que ocorre na doença de Alzheimer. ${ }^{9}$ As EROs e as ERNs (espécies reativas de oxigênio e nitrogênio, respectivamente) produzidas intra e extracelularmente estão entre os principais fatores que promovem a degeneração neuronal na $\mathrm{DA}$, pois provocam alterações em lipídios, principais componentes da bainha de mielina dos neurônios. Além disso, o avançar dos anos leva a uma deposição de íons ferro, zinco e cobre no cérebro, o que compromete a eliminação dos elementos reativos de oxigênio e nitrogênio. ${ }^{10}$

O envelhecimento seria, portanto, secundário ao estresse oxidativo, e as alterações relacionadas com esse processo, principalmente aquelas a nível nuclear, com mudanças no código genético, seriam as responsáveis pelas alterações físicas e deficiências fisiológicas características da senilidade. ${ }^{9}$

A doença de Alzheimer (DA), patologia neurodegenerativa, vem tornando-se frequente nas sociedades devido ao aumento do número de idosos, já que o Alzheimer é mais frequente a partir de 65 anos. ${ }^{9}$ Como descrito nos estudos iniciais de Alois Alzheimer e, posteriormente, por Emil Kraepelin, a DA se caracteriza, do ponto de vista anatomopatológico, pela presença de placas senis ou placas de amiloide e de emaranhados neurofibrilares. $\mathrm{O}$ acúmulo de amiloide ocorre a partir da proteína precursora do amiloide (APP), que apresenta um domínio intracelular e outro extracelular, e pode ser clivada pelas proteases: $\alpha$-secretase, que forma um peptídeo não-amiloidogênico; $\beta$-secretase, que cliva a APP no início do domínio extracelular, formando o APPs $\beta$; e $\gamma$-secretase, que cliva no início da porção intracelular, formando o CTFY. A região transmembrana da APP, livre após clivagem pelas secretases $\beta$ e $\gamma$, é denominada peptídeo $\beta$-amiloide $(\beta A)$ e responsável pela formação das placas amiloides. ${ }^{11-13}$ As presenilinas estão relacionadas com a regulação da proteólise da APP, e mutações em seus genes são grandemente responsáveis pela doença de Alzheimer de surgimento precoce, devido ao maior acúmulo de $\beta A$, assim como mutações nas APP. ${ }^{11,14}$
Com o acúmulo de substância amiloide no espaço extracelular ocorre a degeneração neurofibrilar pela agregação da proteína tau, que quando hiperfosforilada se dissocia dos microtúbulos, onde estava promovendo estabilização, e se agrega sob forma de emaranhados neurofibrilares. ${ }^{10} \mathrm{O}$ hipocampo pertence ao sistema límbico e tem um papel importante na consolidação de informações da memória de curto e longo prazo e na navegação espacial. Na DA, o hipocampo é uma das primeiras regiões do cérebro a sofrer danos, estando a perda de memória e desorientação inclusas nos sintomas precoces..$^{15} \mathrm{Com}$ o avançar da doença, o processo neurodegenerativo expande pelo córtex e atinge outras áreas cerebrais responsáveis por processos cognitivos; característica da evolução da DA. ${ }^{16} \mathrm{~A}$ doença de Alzheimer é a mais frequente doença neurodegenerativa, e vários mecanismos possíveis já foram relacionados e descritos como causas: fatores genéticos, metabólicos, reações inflamatórias, estresse oxidativo, proteínas plasmáticas e cerebrais, entre outros,$^{10} \mathrm{e}$ pesquisas realizadas com esta temática são importantes. Desta maneira, este trabalho objetiva realizar uma revisão sistemática dos últimos dez anos sobre a relação entre a formação de radicais livres e a doença de Alzheimer.

\section{METODOLOGIA}

Para elaboração da introdução, em dezembro de 2015, foram realizadas buscas no Google Acadêmico com os termos "doença de Alzheimer", "radicais livres" e "população idosa no Brasil", tanto separada como concomitantemente. Para que os artigos fossem incluídos, deveriam oferecer as informações necessárias; assim, foram utilizados 13 artigos na introdução, os quais não estão incluídos na revisão sistemática.

A busca dos trabalhos para revisão foi realizada em fevereiro de 2016 nos bancos de dados PubMed, Medline, Lilacs, IBECS e SciELO, utilizando-se os descritores "radicais livres", "doença de Alzheimer" e "envelhecimento", consultados no DeCS, e suas respectivas traduções em inglês e espanhol. Na base de dados PubMed foi utilizado o filtro 10 years, enquanto nas bases Medline, Lilacs, IBECS e SCiELO foram aplicados os filtros artigo e texto disponível.

Inicialmente foram identificados 365 documentos, sendo que desses 252 foram encontrados na base Medline, 111 no PubMed e o restante nas bases de dados Lilacs (1) e IBECS (1). Não foram encontrados trabalhos com os três descritores em SciELO. Posteriormente houve a triagem dos artigos, baseada nas recomendações da declaração PRISMA (Preferred Reporting Items for Systematic Reviews and Meta-Analyses ${ }^{17}$ e realizada por dois pesquisadores de forma independente, com seleção baseada nos critérios de inclusão após avaliação de títulos e resumos. Os critérios definidos foram: publicações entre 2006 e janeiro de 2016; não repetidas entre bases de dados; que abordem o estresse oxidativo no envelhecimento; que relacionem os radicais livres com 
a doença de Alzheimer; publicados em português, inglês ou espanhol. A representação esquemática dos métodos utilizados pode ser observada na Figura 1.

Figura 1-Sequência de identificação, triagem, elegibilidade e inclusão de artigos na revisão, baseada no PRISMA 2009 Flow Diagram

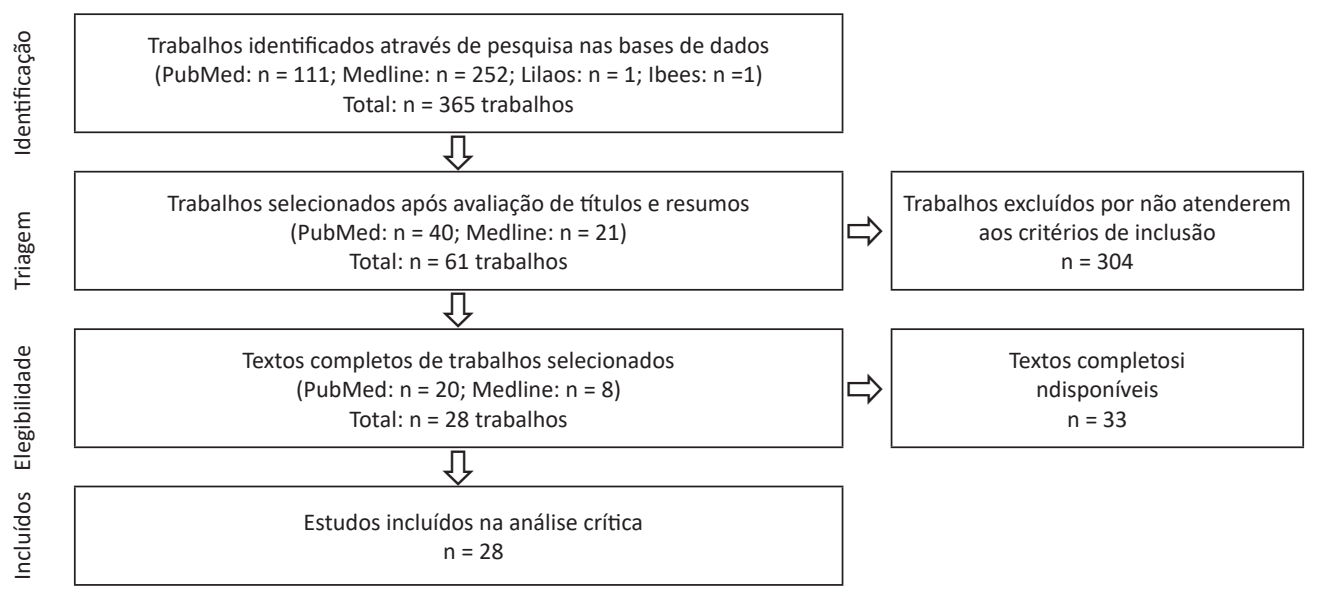

Fonte: Autoria própria

A análise crítica do artigo completo foi realizada também de forma independente por dois pesquisadores, sendo as seguintes informações selecionadas: autor, ano, periódico de publicação, objetivos, metodologia, resultados e outras informações relevantes. A próxima seção apresentará os resultados obtidos.

\section{RESULTADOS}

Foram identificados 28 artigos que preenchem os critérios de inclusão, estando estes organizados na Figura 2 de acordo com o ano de publicação, podendo-se observar uma variabilidade de publicações entre os anos de 2006 e 2016.

A maior parte dos artigos envolve estudos experimentais com animais, sendo principalmente ratos transgênicos (predispostos à doença de Alzheimer, com mutações em genes envolvidos na patogenia da doença), mas também macacos Rhesus e moscas Drosophila. Apenas um dos artigos selecionados envolveu estudo experimental com seres humanos, realizado em 2014.

Figura 2 - Número de artigos incluídos na revisão sistemática segundo o ano de publicação.

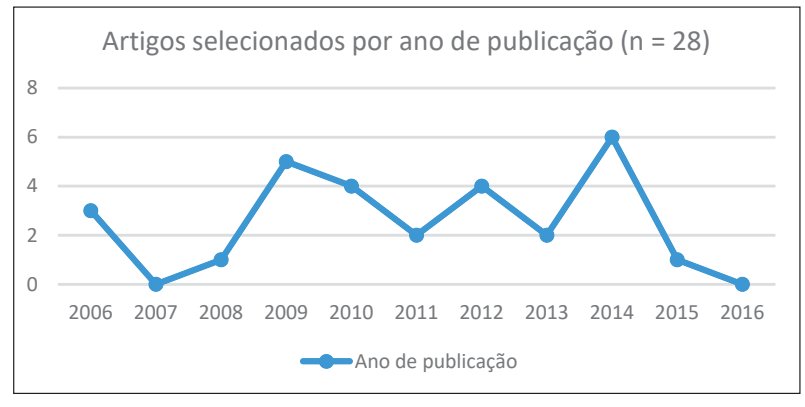

Fonte: Autoria própria
Os 28 estudos analisados também foram subdivididos em eixos temáticos principais, representados na Figura 3. Destes, 14 (50\%) destacaram as alterações decorrentes do estresse oxidativo, $13(46,4 \%)$ abordaram sobre o processo de envelhecimento e suas relações com a doença de Alzheimer, 10 (35,7\%) relataram alterações observadas após administração de amiloide e $8(28,6 \%)$ artigos discorreram sobre possíveis alvos farmacológicos para neuroproteção. A próxima seção abordará a discussão das informações dos artigos selecionados, agrupadas nos eixos temáticos.

Figura 3 - Número de estudos selecionados conforme eixo temático, compreendidos no período de 2006-2016. Pode haver interseção de eixos temáticos em um mesmo artigo.

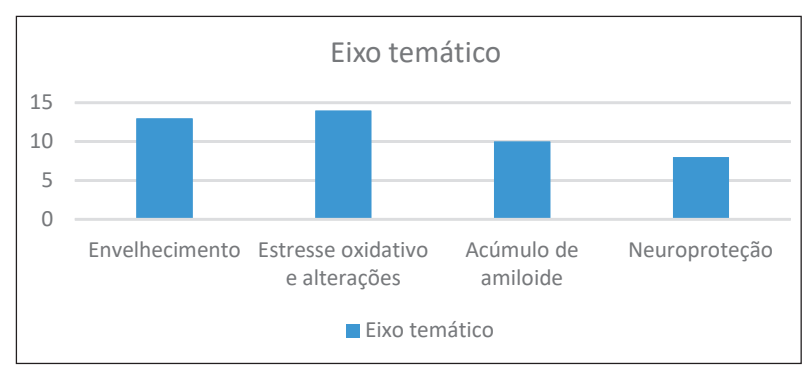

Fonte: Autoria própria

\section{DISCUSSÃO}

\section{Envelhecimento e estresse oxidativo}

O envelhecimento foi relacionado com o aumento de EROs (espécies reativas de oxigênio) devido ao declínio de GSH (glutationa reduzida), que ocorreu tanto pela menor síntese desse antioxidante como pelo aumento de seu consumo no cérebro senescente, ${ }^{15,18}$ e à deficiência na 
enzima peroxirredoxina $3(\operatorname{Prd} \mathrm{x} 3)$, um antioxidante mitocondrial com papel importante na detoxificação do $\mathrm{H}_{2} \mathrm{O}_{2} \cdot{ }^{19}$ Outra situação observada foi a diminuição de NADPH e de regeneração de $\mathrm{NADH}$, que contribui para o desequilíbrio da oxirredução (redox) do tecido cerebral, ${ }^{20}$ alteração que também ocorre com a diminuição da expressão do gene MSRA, levando ao aumento de proteínas oxidadas como a calmodulina, que pode afetar a homeostase e função sinalizadora do $\mathrm{Ca}^{2+} \cdot{ }^{21} \mathrm{~A}$ depleção de antioxidantes - como a diminuição dos níveis de Nrf2 (nuclear erythoid-related fator 2), um fator de transcrição que regula a expressão de proteínas antioxidantes, principalmente o $\mathrm{GSH}^{22}$-e alterações da redox ocorrem principalmente no hipocampo, região importante para a consolidação de informações de memória e localização espacial, causando os sintomas precoces da doença de Alzheimer (DA). ${ }^{15}$

No único estudo com voluntários humanos, que analisou fatores que pudessem interferir na formação de radicais livres durante o envelhecimento, foi observado aumento da lesão cerebral durante a senescência, sendo levemente maior em mulheres do que em homens, além de ativação de receptores do tromboxano $\mathrm{A}_{2}$ por agentes oxidativos, provocando uma vasoconstrição em vários órgãos; entre eles, o cérebro. ${ }^{23} \mathrm{~A}$ degeneração cerebral presente em idosos ocorre pela diminuição dos campos dendríticos e atrofia principalmente do córtex frontal, ${ }^{24}$ que podem estar relacionadas com o acúmulo de alumínio nessa região cortical durante o envelhecimento e consequentes níveis elevados de lipofuscina, que apresenta propriedades citotóxicas, ${ }^{25}$ além de diminuição da expressão dos genes das caspases 3 e 9, provavelmente relacionados com a ineficiência da apoptose no SNC e posteriores deformações cerebrais. ${ }^{24}$

\section{Alterações decorrentes do estresse oxidativo}

Quando o cérebro se encontra em situação de estresse oxidativo ou nitrosativo prolongado, promove maior expressão de genes que possam limitar o dano neuronal ${ }^{26}$ - com o envelhecimento e a atividade diminuída das dismutases, o restante da cadeia respiratória mitocondrial não é mais capaz de compensar os defeitos de produção e não eliminação de radicais livres. ${ }^{27} \mathrm{~A}$ glicólise e fosforilação oxidativa (OxPhos) neuronais provocam lesões, dependendo da intensidade das reações e da competição por substratos entre neurônios: aqueles sem disfunção se sobressaem na competição, intensificam a OxPhos e aumentam seus níveis de EROs, desenvolvendo danos mitocondriais. ${ }^{28} \mathrm{O}$ acúmulo de EROs pode ser identificado em células periféricas e linfócitos esplênicos, que podem ser utilizados como monitoração de eventos patogênicos no tecido cerebral. ${ }^{11}$

O estresse oxidativo provocado por níveis baixos de $\beta A$ pode ser considerado evento precoce na $D A$, enquanto a formação de placas de amiloide, por níveis elevados de $\beta A$, ocorre em estágios mais avançados da doença. ${ }^{11,27}$ Mesmo assim, foi observado que os danos clínicos do estresse oxidativo, como disfunção cognitiva, ocorreram somente após alguns meses em ratos transgênicos, e não imediatamente,$^{20}$ o que justifica o início da patologia da DA em humanos somente décadas após o início das injúrias oxidativas. ${ }^{29} \mathrm{O}$ cérebro é mais suscetível aos danos provocados pelo acúmulo de alumínio e EROs devido à riqueza de ácidos graxos poli-insaturados, que reagem com os radicais livres ${ }^{25}$ levando ao estresse oxidativo e consequente perda neuronal, processo relacionado às doenças neurodegenerativas e ao envelhecimento. ${ }^{12}$

Ratos transgênicos, com mutações para acúmulo de $\beta A$ e desenvolvimento da $D A$, apresentaram precocemente aumento da quantidade de citocromo mitocondrial, um carreador de elétrons essencial na cadeia respiratória, além de maior número das próprias mitocôndrias, provavelmente pela dificuldade na síntese de ATP e compensação dessa ineficiência com aumento de tais organelas. ${ }^{20} \mathrm{~A}$ diminuição bioenergética provavelmente ocorreu devido à exposição de $\beta A$ e ao influxo de cálcio, que despolariza a membrana mitocondrial e provoca disfunção, ${ }^{20,27}$ além de diminuição da atividade da piruvato desidrogenase, o que aumenta a produção de radicais livres e promove a acidificação extracelular pelo acúmulo de piruvato. ${ }^{30}$ Esses eventos são precoces na patogenia da DA, precedendo a formação das placas de amiloide ou depósitos extracelulares e ocorrendo mais intensamente com o decorrer da senescência. ${ }^{30}$

Mutações nos genes da APP ou presenilinas, envolvidas com o desenvolvimento precoce da DA, foram relacionadas com aumento da biossíntese de colesterol ${ }^{31}$ e dos níveis de HNE, um produto da peroxidação lipídica e marcador de estresse oxidativo, ${ }^{11,27}$ e foi observado que essas reações provocaram alterações na homeostase da redox celular. ${ }^{20,31} \mathrm{~A}$ toxicidade, porém, só foi observada em ratos idosos, demonstrando o efeito aditivo do envelhecimento à mutação do gene da presenilina, que predispõe ao aumento de EROs. ${ }^{11}$

O sistema heme oxigenase/biliverdina redutase $(\mathrm{HO} /$ BVR) é um dos primeiros a apresentar regulação positiva no estresse oxidativo, funcionando como neuroprotetor, porém com a administração crônica de $\beta A$ houve diminuição dos níveis de $\mathrm{HO}-2$ (sensor intracelular de alguns agentes oxidativos e nitrosativos) nas áreas comumente envolvidas com a DA, como o hipocampo, e aumento dos níveis de HO-1 (envolvida na resposta ao estresse celular) nas mesmas áreas. ${ }^{26}$

O metilglioxal (MG) é um metabólito produzido por todas as células e altamente oxidante, com propriedades de glicação; quando em níveis elevados, induz regulação negativa de transportadores e canais de $\beta A$, contribuindo para o acúmulo de amiloide no parênquima cerebral. ${ }^{32}$ A $\alpha$-sinucleína (ASN) está envolvida com a melhora da atividade das ERNs e com a patogenia de doenças neurodegenerativas, pois a agregação dessa proteína em protofibrilas devido ao acúmulo de óxido nítrico provoca alterações no transportador de dopamina, ${ }^{33}$ levando a um aumento desse neurotransmissor, que pode ativar 
a formação de radicais livres e esgotar rapidamente a $\mathrm{GSH} .{ }^{18}$

A produção de radicais livres na DA também parece estar relacionada ao sistema xantina/xantina oxidase (X/ $X O D)$, que acumula fragmentos de APP e aumenta os níveis intracelulares de CTF $\alpha$, o qual altera a homeostase do cálcio e provoca estresse oxidativo. ${ }^{12}$ Também foi observado que o acúmulo de homocisteína, formada durante o metabolismo da metionina, provoca estresse oxidativo neuronal, que pode levar à ativação dos canais TRPM2 e TRPV1 hipocampais e consequente apoptose por influxo de $\mathrm{Ca}^{2+} .{ }^{15}$ Outros agentes oxidantes como $\mathrm{H}_{2} \mathrm{O}_{2}$ podem desregular a via MAPK, também induzindo à morte celular. ${ }^{34} \mathrm{~A}$ autofagia sofre regulação positiva pelas EROs, representando uma tentativa das células neuronais lesionadas em se livrarem dos efeitos nocivos do acúmulo de $\beta A$ - assim, o aumento da autofagia e apoptose podem ser benéficos no envelhecimento normal e nos estágios primários da DA, como medida preventiva para eliminação de radicais livres; em estágios tardios, porém, há bloqueio lisossomal, impedindo a eficiência desse mecanismo. ${ }^{35}$

\section{Alterações decorrentes do acúmulo de amiloide}

O acúmulo de $\beta A$ provoca disfunção respiratória e bioenergética por diminuição de piruvato desidrogenase, citocromo oxidase e superóxido dismutase 2 (SOD-2) ${ }^{36,37}$ e aumento de cálcio intracelular após desestabilização do potencial de membrana mitocondrial; ${ }^{27}$ aceleração da senescência de células progenitoras neurais do hipocampo; ${ }^{38}$ ativação do processo inflamatório com consequente liberação de citocinas $^{13}$ e ativação microglial, ${ }^{29,38,39} \mathrm{com}$ todos esses caminhos culminando no aumento de EROs mitocondriais, que possivelmente estariam envolvidos na formação das placas de amiloide. ${ }^{36}$

As EROs promovem a regulação positiva do gene regulador da calcineurina, que inibe a proteína de atuar como fosfatase da proteína tau, resultando em hiperfosforilação da proteína tau e consequente formação de emaranhados neurofibrilares envolvidos na patologia da doença de Alzheimer (DA), causando falha sináptica e apoptose. ${ }^{37}$

$A$ ativação microglial libera ATP, que ativa o canal responsável pelo influxo de $\mathrm{Ca}^{2+}$, ocorrendo oxidação de NADPH e produção de EROs, resultando em dano neuronal e disfunção cerebrovascular. ${ }^{38} \mathrm{O}$ estímulo ocorre mais fortemente a partir da forma fibrilar do amiloide, mas a forma solúvel também é capaz de provocar estímulos, demonstrando que o estresse oxidativo ocorre mesmo no início da DA. ${ }^{29,38} \mathrm{O}$ dano promovido pela ativação microglial ocorre principalmente pela produção de citocinas, quimiocinas e EROs, que também participam da senescência celular ${ }^{39,40}$ e que podem debilitar a via TGFß1-Smad3, envolvida com a modulação da ativação da micróglia, provocando maior produção de agentes oxidantes. ${ }^{40} \mathrm{~A}$ micróglia, porém, apresenta papel benéfico ao promover a limpeza de oligômeros solúveis do cérebro durante a fase precoce da DA e provoca neurodegeneração somente ao ser ativada por formas fibrilares do amiloide, presentes na fase tardia da doença. ${ }^{29}$
O $\beta A$ também pode reagir com o ferro presente no tecido cerebral e transformá-lo em sua forma mais danosa como radical livre, potencializando a formação de EROs, que reagem com proteínas e lipídios formando lipofuscina, um pigmento utilizado como biomarcador de peroxidação lipídica. ${ }^{25}$ A formação de EROs também ocorre com o acúmulo de $\mathrm{H}_{2} \mathrm{O}_{2}$, participante da sinalização celular, que parece estar envolvido no prejuízo cognitivo relacionado à idade. ${ }^{19}$

\section{Neuroproteção}

Sendo as EROs envolvidas com a consolidação das placas de amiloide e com o envelhecimento, pode ser possível desacelerar a senescência com doses moderadas de antioxidantes específicos mitocondriais - que não afetem os agentes oxidantes citosólicos que funcionam como segundo mensageiros ou como protetores contra micro-organismos invasores ${ }^{37}$, como a superexpressão de SOD-2, apesar de ter apresentado eficácia regular;; ou com a identificação de vias que diminuam $\mathrm{O}_{2} \mathrm{O}_{2}$ mitocondrial. ${ }^{19}$

As tentativas de aumentar a expressão de genes envolvidos na diminuição de EROs e o tratamento com antioxidantes com vitamina $\mathrm{E}$ e/ou $\mathrm{C}$ falharam em meIhorar a cognição na DA, indicando que a superexpressão de antioxidantes pode não ser a melhor tentativa de neuroproteção. ${ }^{22}$ Isso porque, segundo os autores, a presença de EROs pode ser um acontecimento tardio, fora do alvo de neuroproteção, enquanto metas mais precoces como alterações no redox oxidativo celular provavelmente seriam mais controladoras da doença. A utilização de nicotinamida, uma precursora sintética de $\mathrm{NAD}^{+}$, demonstrou aumento dos níveis de $\mathrm{NADPH}$ e reversão do estado oxidativo da célula, aumentando a concentração de antioxidantes e diminuindo o EROs, descaracterizando a DA. ${ }^{20}$

Tratamentos com anti-inflamatórios não esteroidais que reduzem toda a inflamação e a ação da micróglia não produzem ganho líquido, pois também eliminam os efeitos benéficos microgliais de limpeza, sendo necessário o bloqueio de receptores específicos e vias participantes no processo da DA para tratamento efetivo. ${ }^{29}$ Também há a teoria de que em doenças neurodegenerativas há o acúmulo de glutamato por liberação excessiva ou recaptação diminuída, sendo o bloqueio de receptores NMDA (de glutamato) especulado como alvo terapêutico, ${ }^{24}$ assim como a apolipoproteína D, um carreador lipídico que é encontrado em maiores níveis em células da glia do cérebro em estresse oxidativo e pode estar relacionada com a neuroproteção. ${ }^{41}$

\section{CONCLUSÕES}

No envelhecimento há aumento do estado oxidativo celular, o que provoca mecanismos que aumentam ainda mais a produção de radicais livres. Os peptídeos $\beta$-amiloides $(\beta A)$, em suas formas solúveis e posterior- 
mente fibrilares, provocam disfunção mitocondrial, aceleram a senescência celular, provocam processo inflamatório e ativam a micróglia. Tais processos causam o acúmulo de radicais livres na região hipocampal, e o estado oxidativo auxilia a formação de placas extracelulares de amiloide e fosforilação da proteína tau, formando os emaranhados neurofibrilares característicos da doença de Alzheimer.

Foi observado que, em dez anos de publicações, os resultados variaram conforme a metodologia dos estudos, corroborando o estresse oxidativo, comum no envelhecimento e na doença de Alzheimer.

Assim, novas teorias e novos trabalhos deverão surgir, os quais abranjam e complementem todas as observações pontuadas.

\section{REFERÊNCIAS}

1. LAMARCA, G.; VETTORE, M. O envelhecimento da população brasileira: a nova transição demográfica. 2012. Disponível em: <http://dssbr. org/site/?p=10690>. Acesso em: 24 ago. 2016.

2. NASRI, F. O envelhecimento populacional no Brasil. Einstein, São Paulo, v. 6, supl. 1, p. S4-6, 2008.

3. JORM, A. F.; JOLLEY, D. The incidence of dementia: a meta-analysis. Neurology, New York, v. 51, n.3, p. 728-733, Sept. 1998.

4. SILVA, W. J. M. da.; FERRARI, C. K. B. Metabolismo mitocondrial, radicais livres e envelhecimento. Rev. bras. geriatr. gerontol., Rio de Janeiro, v. 14, n. 3, p. 441-451, 2011.

5. PIOTROWSKA, A.; BARTNIK, E. The role of reactive oxygen species and mitochondria in aging. Postep. biochem., Warzaw, p. 240-247, Jan. 2014.

6. FERREIRA, A. L. A.; MATSUBARA, L. S. Radicais livres: conceitos, doenças relacionadas, sistema de defesa e estresse oxidativo. Rev. Assoc. Med. Bras., São Paulo, v. 43, n. 1, p. 61-68, mar. 1997.

7. CARDOSO, B. R.; COZZOLINO, S. M. F. Estresse oxidativo na doença de Alzheimer: o papel das vitaminas C e E. Nutrire Rev. Soc. Bras. Aliment. Nutr., São Paulo, v. 34, n. 3, p. 249-259, dez. 2009.

8. CERQUEIRA, F. M.; MEDEIROS, M. H. G. de.; AUGUSTO, O. Antioxidantes dietéticos: controvérsias e perspectivas. Quím. nova, São Paulo, v. 30, n. 2, p. 441-449, abr. 2007.

9. SERENIKI, A.; VITAL, M. A. B. F. A doença de Alzheimer: aspectos fisiopatológicos e farmacológicos. Rev. psiquiatr. Rio Gd. Sul, Porto Alegre, v. 30, n. 1, 2008.

10. CAVALCANTI, J. L. de S.; ENGELHARDT, E. Aspectos da fisiopatologia da doença de Alzheimer esporádica. Rev. bras. neurol., Rio de Janeiro, v. 48, n. 4, p.21-29, out. 2012.

11. SCHUESSEL, K. et al. Aging sensitizes toward ROS formation and lipid peroxidation in PS1M146L transgenic mice. Free radic. biol. med., New York, v. 40, n. 5, p. 850-862, Mar. 2006.

12. RECUERO, M. et al. A free radical-generating system regulates APP metabolism/processing. Febs lett., Amsterdam, v. 584, n. 22, p. 46114618, Oct. 2010.

13. KO, Shun-Yao et al. Advanced glycation end products enhance amyloid precursor protein expression by inducing reactive oxygen species. Free radic. biol. med., New York, v. 49, n. 3, p. 474-480, Ago. 2010.

14. FRIDMAN, C. et al. Alterações genéticas na doença de Alzheimer. Rev. psiquiatr. clín., São Paulo, v. 31, n. 1, p. 19-25, 2004.
15. ÖVEY, I. S.; NAZIROĞLU, M. Homocysteine and cytosolic GSH depletion induce apoptosis and oxidative toxicity through cytosolic calcium overload in the hippocampus of aged mice: Involvement of TRPM2 and TRPV1 channels. Neuroscience, [S.I], v. 284, p.225-233, Jan. 2015.

16. FORLENZA, O. V. Tratamento farmacológico da doença de Alzheimer. Rev. Psiquiatr. Clín., São Paulo, v. 32, n. 3, p.137-148, abr. 2005.

17. MOHER, D. et al. Preferred Reporting Items for Systematic Reviews and Meta-Analyses: The PRISMA Statement. J. clin. epidemiol., Oxford, v. 62, n. 10, p.1006-1012, Oct. 2009.

18. ZHU, Y.; CARVEY, P. M.; LING, Z. Age-related changes in glutathione and glutathione-related enzymes in rat brain. Brain res., Amsterdam, v. 1090, n. 1, p. 35-44, May 2006.

19. CHEN, L.; NA, R.; RAN, Q. Enhanced defense against mitochondrial hydrogen peroxide attenuates age-associated cognition decline. Neurobiol. aging, New York, v. 35, n. 11, p. 2552-2561, Nov. 2014.

20. GHOSH, D. et al. A reversible early oxidized redox state that precedes macromolecular ROS damage in aging nontransgenic and 3xTg-AD mouse neurons. J. neurosc., Baltimore, v. 32, n. 17, p. 58215832, Apr. 2012.

21. TODA, T. et al. Proteomic approaches to oxidative protein modifications implicated in the mechanism of aging. Geriatr. gerontol. int., Tokyo, v. 10, supl. 1, p. S25-31, Jan. 2010.

22. GHOSH, D.; LEVAULT, K. R.; BREWER, G. J. Dual-energy precursor and nuclear erythroid-related factor 2 activator treatment additively improve redox glutathione levels and neuron survival in aging and Alzheimer mouse neurons upstream of reactive oxygen species. Neurobiol. aging, New York, v. 35, n. 1, p.179-190, Jan. 2014.

23. PESKIND, E. R. et al. Influence of lifestyle modifications on age-related free radical injury to brain. Jama Neurol., Chicago, v. 71, n. 9, p.1150-1154, Sept. 2014.

24. KAROLCZAK, D. et al. Memantine - neuroprotective drug in aging brain. Pol. j. pathol., Krakow, v. 3, p. 196-203, 2013.

25. TRIPATHI, S. et al. Influence of age on aluminum induced lipid peroxidation and neurolipofuscin in frontal cortex of rat brain: a behavioral, biochemical and ultrastructural study. Brain res., Amsterdam, v. 1253, p.107-116, Feb. 2009.

26. BARONE, E. et al. Heme oxygenase-1 posttranslational modifications in the brain of subjects with Alzheimer disease and mild cognitive impairment. Free radic. biol. med., New York, v. 52, n. 11-12, p. 2292-2301, June 2012.

27. HAUPTMANN, S. et al. Mitochondrial dysfunction: An early event in Alzheimer pathology accumulates with age in $A D$ transgenic mice. Neurobiol. aging, New York, v. 30, n. 10, p.1574-1586, Oct. 2009.

28. DEMETRIUS, L. A.; SIMON, D. K. An inverse-warburg effect and the origin of alzheimer's disease. Biogerontology, Dordrecht, v. 13, n. 6 , p. 583-594, Oct. 2012.

29. LEUNG, E. et al. Microglia activation mediates fibrillar amyloid- $\beta$ toxicity in the aged primate cortex. Neurobiol. aging, New York, v. 32, n. 3, p. 387-397, Mar. 2011.

30. YAO, J. et al. Mitochondrial bioenergetic deficit precedes Alzheimer's pathology in female mouse model of Alzheimer's disease. Proc. Natl. Acad. Sci. U. S. A., Washington, v. 106, n. 34, p.1467014675, Ago. 2009.

31. RECUERO, M. et al. A free radical-generating system induces the cholesterol biosynthesis pathway: a role in Alzheimer's disease. Aging cell, Oxford, v. 8, p.128-139, Jan. 2009. 
32. TÓTH, A. E. et al. Compounds blocking methylglyoxal-induced protein modification and brain endothelial injury. Arch. med. res., México, v. 45, n. 8, p.753-764, Nov. 2014.

33. ADAMCZYK, A.; KAÜMIERCZAK, A.; STROSZNAJDER, J. B. $\alpha$-Synuclein and its neurotoxic fragment inhibit dopamine uptake into rat striatal synaptosomes. Neurochem. int., Oxford, v. 49, n. 4, p.407-412, Sept. 2006.

34. ZHANG, R.et al. Screening of microRNAs associated with Alzheimer's disease using oxidative stress cell model and different strains of senescence accelerated mice. J. neurol. sci., Amsterdam, v. 338, n. 1-2, p.57-64, Mar. 2014.

35. LIPINSKI, M. M. et al. Genome-wide analysis reveals mechanisms modulating autophagy in normal brain aging and in Alzheimer's disease. Proc. Natl. Acad. Sci. U. S. A., Washington, v. 107, n. 32, p.14164-14169, July 2010.

36. MASSAAD, C. A. et al. Overexpression of SOD-2 reduces hippocampal superoxide and prevents memory deficits in a mouse model of Alzheimer's disease. Proc. Natl. Acad. Sci. U. S. A., Washington, v. 106, n. 32, p.13576-13581, Ago. 2009.
37. SKULACHEV, V. P. Mitochondria-Targeted Antioxidants as Promising Drugs for Treatment of Age-Related Brain Diseases. J. alzheimer dis., Amsterdam, v. 28, n. 2, p. 283-289, 2012.

38. LEE, H. G.et al. Microglial P2X 7 receptor expression is accompanied by neuronal damage in the cerebral cortex of the APP swe /PS1dE9 mouse model of Alzheimer's disease. Exp. mol. med., Seoul, v. 43, n. 1, p.7-14, 2011.

39. HE, N. et al. Amyloid- $\beta 1-42$ oligomer accelerates senescence in adult hippocampal neural stem/progenitor cells via formylpeptide receptor 2. Cell Death Dis, [S.I.], v. 4, n. 11, p.924-934, 21 nov. 2013.

40. TICHAUER, J. E. et al. Age-dependent changes on TGF $\beta 1$ Smad3 pathway modify the pattern of microglial cell activation. Brain behav. immun., San Diego C A, v. 37, p.187-196, mar. 2014.

41. MUFFAT, J.; WALKER, D. W.; BENZER, S. Human ApoD, an apolipoprotein up-regulated in neurodegenerative diseases, extends lifespan and increases stress resistance in Drosophila. Proc. Natl. Acad. Sci. U. S. A., Washington, v. 105, n. 19, p.7088-7093, May 2008.

Submetido em: $11 / 03 / 2017$

Aceito em: 13/07/2017 